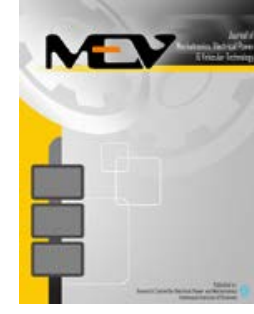

\title{
Characteristics analysis of interior and inset type permanent magnet motors for electric vehicle applications
}

\author{
Pudji Irasari $^{\mathrm{a}, *}$, Ketut Wirtayasa ${ }^{\mathrm{a}, \mathrm{b}}$, Puji Widiyanto ${ }^{\mathrm{a}}$, \\ Muhammad Fathul Hikmawan ${ }^{a}$, Muhammad Kasim ${ }^{\text {a, c }}$ \\ ${ }^{a}$ Research Centre for Electrical Power and Mechatronics, Indonesian Institute of Sciences \\ Jl. Cisitu No. 154D, Bandung, 40135, Indonesia \\ ${ }^{b}$ Department of Electrical Engineering, National Taiwan University of Science and Technology \\ No. 43, Section 4, Keelung Rd, Da' an District, Taipei City, 106, Taiwan \\ ${ }^{c}$ School of Electrical Engineering and Telecommunications, University of New South Wales \\ 330 Anzac Parade, Kensington NSW 2033, Australia
}

Received 5 January 2021; Accepted 2 June 2021; Published online 31 July 2021

\begin{abstract}
Permanent magnet motors (PMMs) are widely used in electric vehicles because of their benefits. Based on the permanent magnet topologies on the rotor, PMMs are classified into three types: surface mounted PMM, inset PMM, and interior PMM. This paper discusses a comparison of the characteristics of interior and inset types of PMMs for electric vehicle applications. The study aims to find out the effect of the rotor construction on the magnetic characteristics, torque-speed characteristics, and cogging torque. Simulations were carried out analytically and numerically using the FEMM 4.2 software. The simulation results at the base speed show that the interior PMM generates a higher torque but with a lower rotation, namely $56.47 \mathrm{Nm}$ and $3162 \mathrm{rpm}$, respectively, while the inset PMM produces higher rotation $4200 \mathrm{rpm}$ but lower output torque of $46.01 \mathrm{Nm}$. However, with a higher saliency ratio, the interior PMM produces higher maximum torque and speed at both constant torque and field weakening regions than the PMM inset, which is $92.87 \mathrm{Nm}$ and $6310 \mathrm{rpm}$, consecutively. In terms of cogging torque, the interior PMM raises it slightly higher $(2.90 \mathrm{Nm})$ than the inset PMM $(1.93 \mathrm{Nm})$. The results conclude that, in general, the interior PMM shows better performance in all studied regions and is preferable for electric vehicle applications.
\end{abstract}

@ 2021 Research Centre for Electrical Power and Mechatronics - Indonesian Institute of Sciences. This is an open access article under the CC BY-NC-SA license (https://creativecommons.org/licenses/by-nc-sa/4.0/).

Keywords: permanent magnet motor; interior PMM; inset PMM; torque-speed characteristic; cogging torque.

\section{Introduction}

Electric vehicles require traction motors having simple construction that makes them easy to maintenance and manufacture and have high efficiency, reasonable price, and high torque density in a wide speed range [1][2]. However, PMMs develop torque ripple stemming from, among others, the cogging torque and the non-sinusoidal electromotive force waveform (EMF) in the air gap. This torque ripple causes acoustic noise and vibration, which can reduce the performance of position control and speed control systems, especially at low speeds and high load torque [3][4][5]. Studies to eliminate or reducing cogging torque in PMMs were discussed by [6][7]. A

\footnotetext{
* Corresponding Author. Tel: +62-22-2503055

E-mail address: pirasari@yahoo.com
}

sinusoidal EMF waveform can be obtained by arranging a sinusoidal winding distribution in the stator slots. Brushless ac electric motors generate lower electromagnetic torque ripple (about 2 to $8 \%$ ) than brushless dc electric motors (about 7 to $30 \%$ ) [8].

The improvement of motor performance presented by the torque-speed characteristic is mainly to get an extensive field weakening (FW) range with high torque, as is conducted by [9][10] through controlling the current. However, contradictive problems are usually faced when trying to fix one of the parameters. For example, the FW region can be extended by reducing the flux linkage, but this resulting in lower output torque. Also, output torque can be improved by increasing the saliency ratio $\left(L_{q} / L_{d}\right)$, but it does not affect the width of the FW region [11]. 
There are three possible permanent magnet topologies on the rotor, namely surface mounted, inset, and interior. Of the three topologies, the interior type provides easy control of field attenuation, highest mechanical durability, lowest eddy current loss but higher manufacturing costs. In contrast, surface-mounted permanent magnet structures are less expensive but have low mechanical resistance and high eddy current loss. Between the two types is the inset permanent magnet rotor with higher mechanical resistance and lower eddy current loss than the surface-mounted type but lower manufacturing costs compared to interior permanent magnet structures [12][13]. The most applied type as a traction motor for electric vehicles is the interior PMM [14].

The many choices of permanent magnet configurations on the rotor make it challenging to study, especially its effect on machine performance. A study conducted by [15] developed an analytical method for the magnetic vector potential applied to MMP $150 \mathrm{~W}$ with surface mounted and inset rotor types, respectively, then compared their magnetic characteristics and cogging torques. Meanwhile, [16] studied surface-mounted permanent magnet types using an inner and outer rotor, each varied with segment and non-segment magnetic poles. The characteristics observed include the output torque and core loss.

This paper will analyze the PMM characteristics using interior and inset rotor structures. The proposed rotor construction of the inset PMM is intended for widening the field weakening zone. The motors are designed with a base speed of $1000 \mathrm{rpm}$ and use defined stator construction. The study aims to learn the effect of the rotor topology on motor performance include magnetic characteristics, torque-speed characteristics, and cogging torque. The simulations will be conducted analytically and numerically by employing FEMM 4.2 software.

\section{Materials and Methods}

\section{A. Motor construction}

The interior and inset PMMs in Figure 1 have identical dimensions and slightly different rotor construction. In the interior PMM, the permanent magnets are thoroughly buried in the rotor body to prevent it from coming off due to centrifugal force when the motor rotates (Figure 1a). Besides, magnets do not fatigue quickly so that the operating life of the machine can be longer. In the inset PMM, the upper sides of the permanent magnets are exposed to the air gap. It appears that they are inside the rotor slots with their surfaces are held in place by the flanking top teeth to get a better mechanical strength against the centrifugal force (Figure $1 \mathrm{~b}$ ).

Detailed dimensions of the stator and rotor are shown in Figure 2 and Table 1. The stator and rotor use grade M-19 of silicon steel lamination with a maximum magnetic flux density of $2.3 \mathrm{~T}$. While the permanent magnet is of $\mathrm{NdFeB}$ type grade $35 \mathrm{H}$ with a remanent flux density $B_{r}$ of $1.17 \mathrm{~T}$.

Aside from using the same material and stator construction, several constraints are set to achieve a fair comparison, namely:

- base frequency, base speed, and current density are $50 \mathrm{~Hz}, 1000 \mathrm{rpm}$, and $3 \mathrm{~A} / \mathrm{mm}^{2}$ consecutively,

- $\quad$ Stator fill factor $\leq 4$ (as close as possible),

- Phase terminal voltage $\leq 144 \mathrm{~V}$ (as close as possible).

Furthermore, the design stages are carried out in the order depicted in Figure 3.

\section{B. Parameter calculations}

Under the no-load condition, magnetic flux per pole generated by the permanent magnet in the rotor $\Phi_{M}$ is [17]:

$\Phi_{M}=\frac{B_{m g} D_{i} L_{i}}{p}(\mathrm{~Wb})$

where $D_{i}=2 \times I_{\mathrm{i}}=$ inner stator diameter $(\mathrm{m}), B_{m g}$ is maximum air gap flux density $(\mathrm{T}), p$ is number of pole pairs $=3$ pairs.

Furthermore, the maximum linkage flux per phase $\psi_{M}$ owing to the permanent magnet is expressed by:

$\psi_{M}=k_{w} N_{p h} \Phi_{M}(\mathrm{~Wb})$

where $k_{W}$ is the winding factor, $N_{p h}$ is the phase winding numbers.

From (2), the induced voltage per phase $E_{p h}$ can be written as

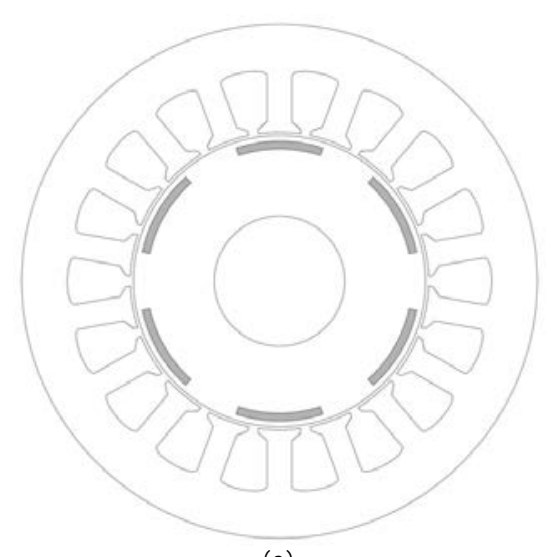

(a)

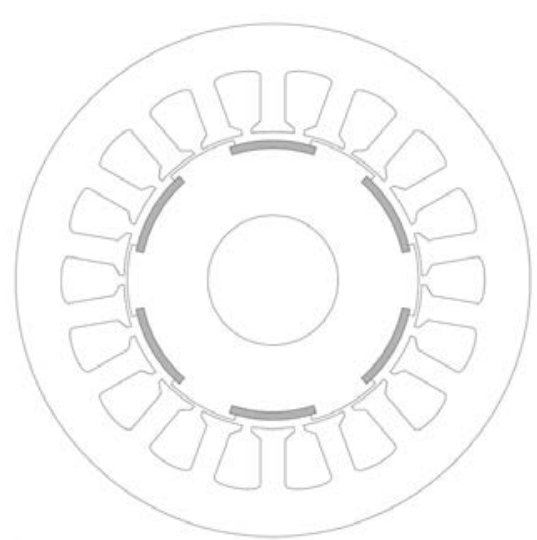

(b)

Figure 1. PMM topology with. (a) Interior permanent magnet rotor; (b) Inset permanent magnet rotor 
Table 1.

PMM Dimensions

\begin{tabular}{lrll}
\hline Description, notation & Value $(\mathrm{m})$ & Description, notation & Value $(\mathrm{m})$ \\
\hline Stator outer radius, $I_{\mathrm{o}}$ & 0.0830 & Upper slot width, $W_{\mathrm{s} 1}$ & 0.0091 \\
Stator inner radius, $I_{\mathrm{i}}$ & 0.0480 & Lower slot width, $W_{\mathrm{s} 2}$ & 0.0142 \\
Effective length of stator core, $L_{\mathrm{i}}$ & 0.2500 & Stator yoke width, $y_{\mathrm{s}}$ & 0.0150 \\
Stator teeth width, $W_{\mathrm{ts}}$ & 0.0080 & Rotor radius, $I_{\mathrm{r}}$ & 0.0470 \\
Upper top teeth height, $h_{\mathrm{os}}$ & 0.0015 & Surface magnet radius, $I_{\mathrm{mo}}$ \\
Lower top teeth height, $h_{\mathrm{w}}$ & 0.0020 & Permanent magnet height, $h_{\mathrm{m}}$ \\
Stator slot width, $W_{\mathrm{os}}$ & 0.0030 & Shaft radius, $I_{\mathrm{sh}}$ & \\
Stator slot depth, $h_{\mathrm{s}}$ & 0.0166 & \\
\hline
\end{tabular}

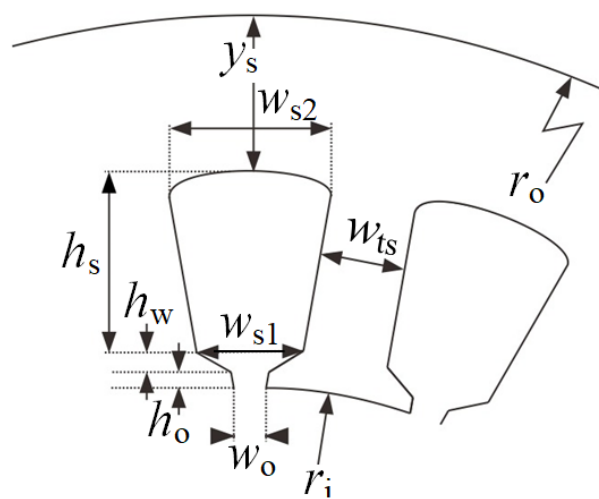

(a)

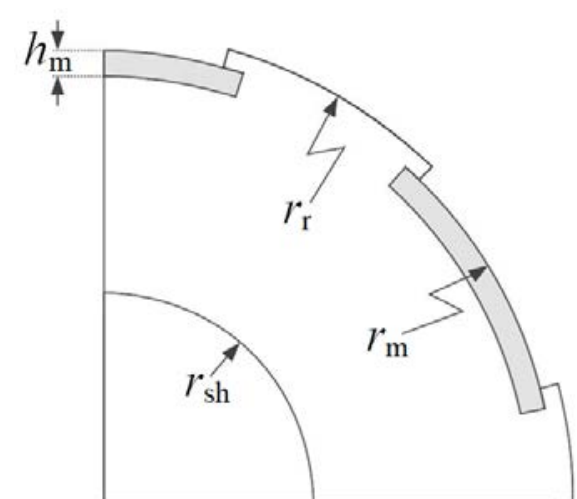

(b)

Figure 2. Detailed dimension of the (a) stator; (b) rotor represented by the inset PMM
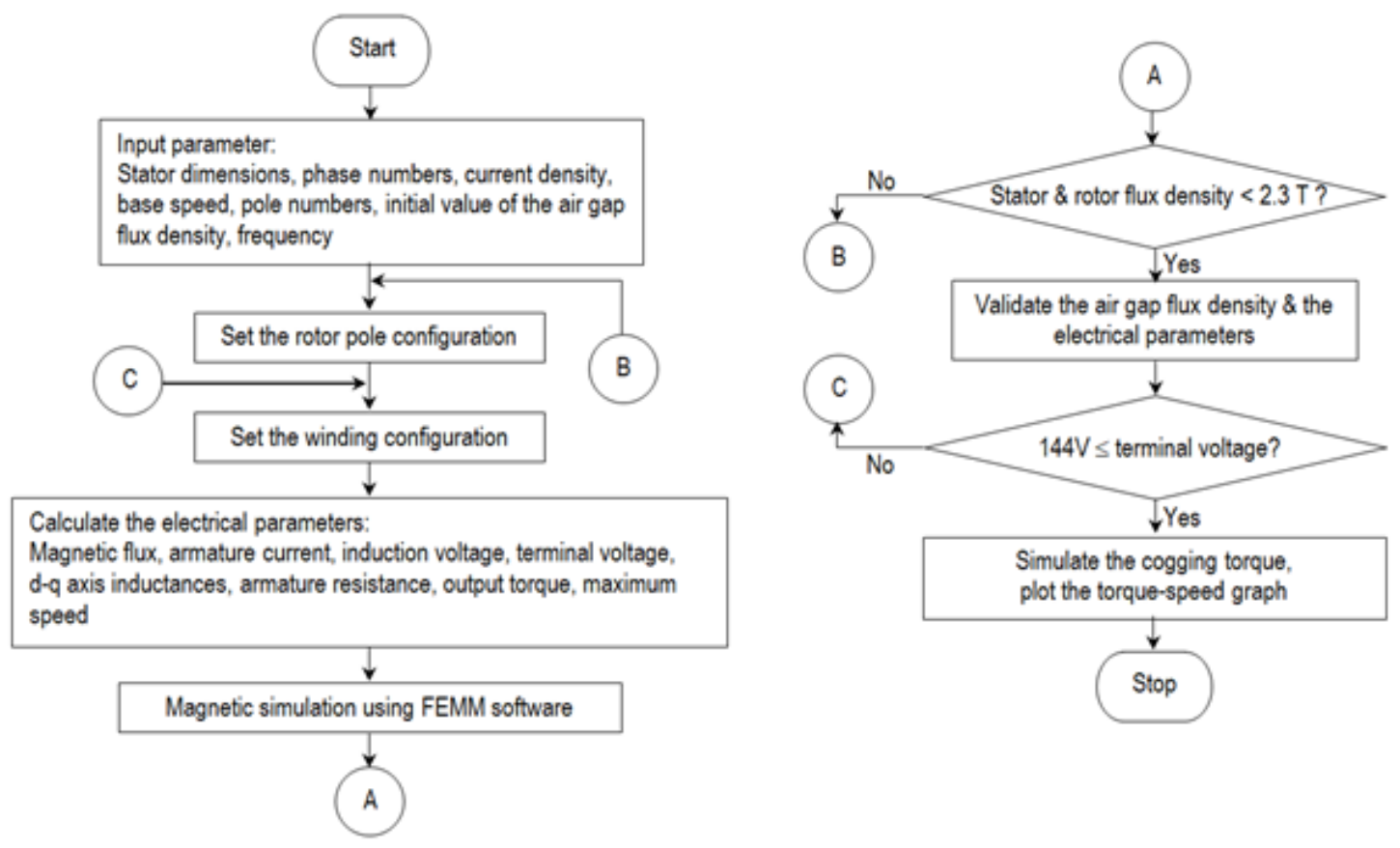

Figure 3. The design flowchart

$E_{\mathrm{ph}}=\frac{1}{\sqrt{2}} \omega \Psi_{M}(\mathrm{~V})$

where $\omega=2 \pi f$, and $f$ is nominal frequency $=50 \mathrm{~Hz}$.

The phase leakage reactance $X_{1}$ is obtained from:

$X_{1}=4 \pi \mu_{0} \frac{N_{\mathrm{ph}}^{2} L_{\mathrm{i}}}{p q}\left(\lambda_{1 s}+\frac{l_{1 \mathrm{e}}}{L_{\mathrm{i}}} \lambda_{1 \mathrm{e}}+\lambda_{1 \mathrm{~d}}+\lambda_{1 \mathrm{t}}\right)$

where $q$ is the number of slots per pole per phase, $\mu_{0}$ is the magnetic permeability of vacuum $=0.4 \pi \times 10^{-6}$ $\mathrm{H} / \mathrm{m}, \lambda_{1 \mathrm{~s}}$ is the slot leakage permeance, $\lambda_{1 \mathrm{e}}$ is the end winding leakage permeance, $l_{1 \mathrm{e}}$ is the length of end winding, $\lambda_{1 \mathrm{~d}}$ is the differential leakage permeance, $\lambda_{1 \mathrm{t}}$ is the tooth-top leakage permeance.

The mutual reactances of the $\mathrm{d}$ - and q-axis are given by (5) and (6) [18]:

$X_{\mathrm{ad}}=4 m \mu_{0} f \frac{\left(N_{\mathrm{ph}} k_{w}\right)^{2}}{\pi p} \frac{\tau L_{\mathrm{i}}}{g^{\prime}} k_{\mathrm{fd}} \quad(\Omega)$

$X_{\mathrm{aq}}=4 m \mu_{0} f \frac{\left(N_{\mathrm{ph}} k_{w}\right)^{2}}{\pi p} \frac{\tau L_{\mathrm{i}}}{g_{q}^{\prime}} k_{\mathrm{fq}} \quad(\Omega)$ 
with $\tau$ is the pole pitch $(\mathrm{m}), g^{\prime}, g_{q}^{\prime}$ are d- and q-axis of the equivalent air gap $(\mathrm{m}), k_{\mathrm{fd}}, k_{\mathrm{fq}}$ are the form factors of the $\mathrm{d}$ - and q-axis armature reaction.

The $\mathrm{d}$ - and q-axis synchronous reactances are calculated with (7) and (8), respectively:

$X_{\mathrm{sd}}=X_{1}+X_{\mathrm{ad}}(\Omega)$

$X_{\mathrm{sq}}=X_{1}+X_{\mathrm{aq}}(\Omega)$

The phase terminal voltage $V$ is

$V=\sqrt{\left(E_{\mathrm{ph}}+I_{\mathrm{a}} R_{\mathrm{a}}\right)^{2}+\left(I_{\mathrm{a}} X_{\mathrm{sd}}\right)^{2}+\left(I_{\mathrm{a}} X_{\mathrm{sq}}\right)^{2}}(\mathrm{~V})$

where $I_{\mathrm{a}}$ is the phase armature current $(\mathrm{A})$, and $R_{\mathrm{a}}$ is the phase armature resistance $(\Omega)$.

\section{Torque-speed characteristics}

Figure 4 shows a sine wave PMM operation, where from 0 to $n_{b}$, the motor develops maximum torque with the maximum armature current $I_{d}$ supplied by the converter, oriented along the q-axis. Furthermore, from $n_{b}$ to $n_{\max }$, the armature current partially demagnetizes the permanent magnet, which is called field weakening operation (Figure 4a). In this state, the voltage $V$ is kept constant by utilizing the d-axis demagnetization armature reaction in a negative direction (Figure $4 \mathrm{~b}$ ), and the torque decreases until it reaches zero [2].

The correlation between the armature current $I_{a}$ with the $\mathrm{d}$ - and q-axis currents $I_{d}$ and $I_{q}$ are expressed by [19]:

$I_{d}=-I_{a} \sin \gamma(\mathrm{A})$

$I_{q}=I_{a} \cos \gamma(\mathrm{A})$

The current vector angle $\gamma$ correlates proportionally to the motor speed. If the current $I_{d}$ increases in the negative direction, the current $I_{q}$ decreases. The d-axis flux linkage reaches a minimum value when $I_{d}$ equals nominal current, and $I_{q}$ becomes zero. Torque and power are zero, and maximum speed results in $n_{\max }$ [20].

The current angle $\gamma$ is obtained from:

$\gamma=\sin ^{-1}\left[\frac{k_{x}^{2} e_{m}^{2}+k_{x}^{2}\left(L / e_{m}\right)^{2}-1}{2 k_{x}^{2} L}\right]$

with

$e_{m}=\frac{E_{o}}{V_{t}}$

$$
\begin{aligned}
& k=\frac{1}{e_{m} \sqrt{1-e_{m}^{2}}}=\frac{n_{\max }}{n_{\text {nom }}} \\
& L=e_{m} \sqrt{1-e_{m}^{2}}
\end{aligned}
$$

where $e_{m}$ is a ratio of per-unit open-circuit voltage $E_{0}$ to maximum r.m.s a.c converter voltage $V_{t}$ as the base voltage (pu), the maximum $k_{x}=k$ and the maximum $\gamma=90^{\circ}, n_{\max }$ is the maximum speed (rpm), and $n_{n o m}$ is the nominal speed $=6000 \mathrm{rpm}$.

The output torque is

$T=\frac{3 p}{\omega}\left[E_{\mathrm{q}} I_{\mathrm{q}}+\left(X_{\mathrm{sd}}-X_{\mathrm{sq}}\right) I_{\mathrm{d}} I_{\mathrm{q}}\right](\mathrm{Nm})$

where: $E_{q}=E_{p h}$

The first term is permanent magnet torque, related to the linkage flux that generates the induced voltage Eq, while the second term is the reluctance torque affected by inductance/reactance and currents on the $\mathrm{d}$ and $\mathrm{q}$ axes [21].

\section{Cogging torque}

Cogging torque arises due to the interaction between the rotor magnetic flux and the reluctance in the air gap, whose value varies owing to the stator slot geometry. The cogging torque $T_{c}$ is expressed by equation [22]:

$T_{\mathrm{c}}=-\frac{1}{2} \phi_{g}^{2} \frac{d \mathcal{R}}{d \theta}(\mathrm{Nm})$

where $\phi_{g}$ is magnetic flux (Wb), $\mathcal{R}$ is air gap reluctance (A.t/Wb), and $\theta$ is rotor position (mechanical degree).

Cogging torque occurs at no-load conditions. Therefore, the magnetic flux in the air gap is entirely generated by rotor poles. The change of reluctance occurs periodically, so does the cogging torque. The magnetic strength used is proportional to the produced cogging torque. In this study, cogging torque is obtained through numerical simulation.

\section{Results and Discussions}

The results of calculations and simulations of motor performance comprise magnetic characteristics, torque-speed characteristics, as well as cogging torque, which will be described in detail in the following subsections.

\section{A. Magnetic characteristics}

Figure 5 show the magnetic distributions of the interior and inset PMMs, respectively, where the

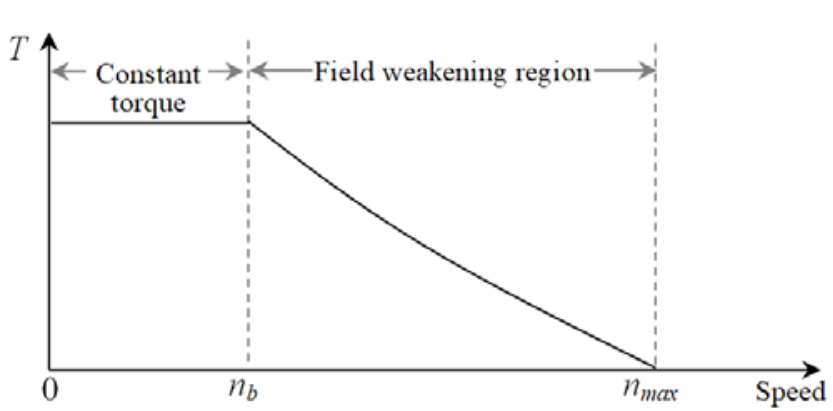

(a)

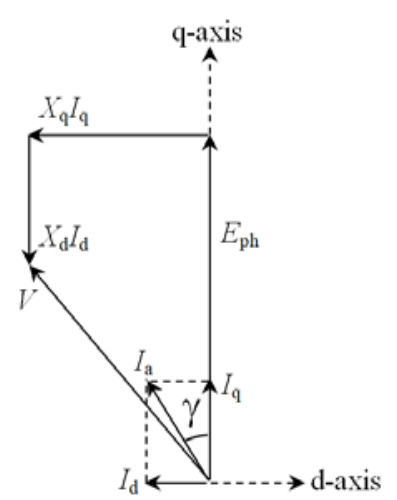

(b)

Figure 4. A sine wave PMM operation. (a) torque-speed characteristic; (b) demagnetization phasor diagram d-axis current $I_{d}$ 


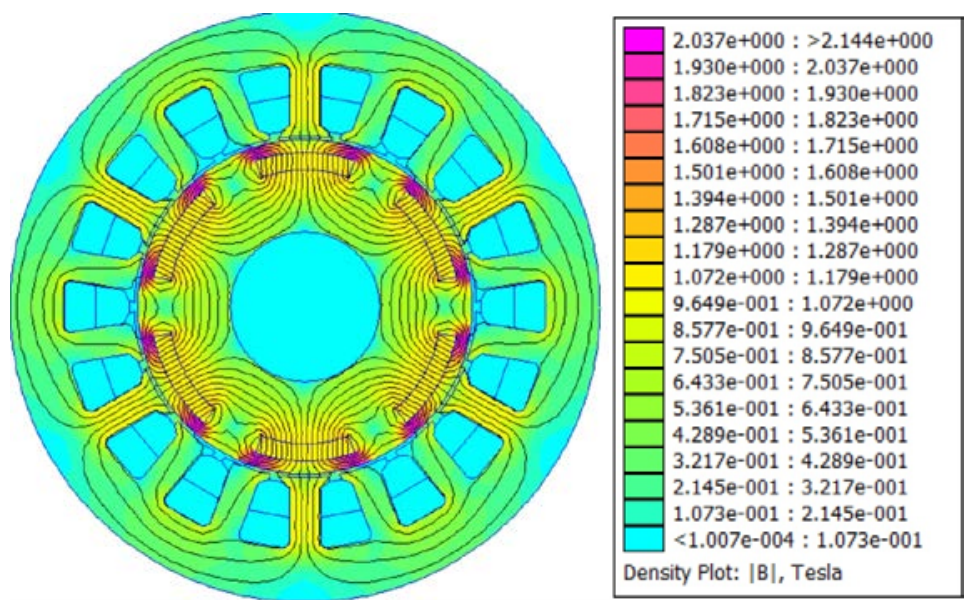

(a)

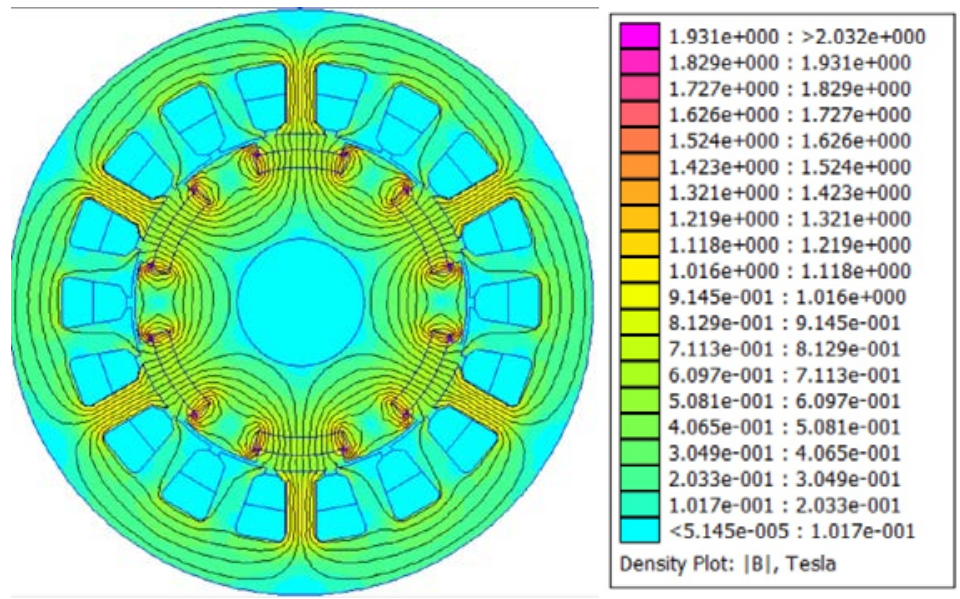

(b)

Figure 5. Magnetic flux distribution in no-load condition. (a) Interior PM motor; (b) Inset PM motor

most magnetic flux crossing the air gap towards the stator teeth comes from the middle part of the permanent magnet surface. The magnetic flux then flows to the stator yoke and divides into two directions, each interacting with the opposing pole next to it by forming a closed loop. On the other hand, it seems that part of the magnetic flux from both sides of the adjoining magnet tends to flow through the rotor body, having higher magnetic permeability $\left(\mu_{T}=4000\right)$ than air $\left(\mu_{T}=1\right)$, to interact with the adjacent poles. It causes a flux leakage indicated by the high flux concentration around the magnet edges. In the interior PMM (Figure 5a), the density of the leakage flux is higher $(2.037 \mathrm{~T})$ than that in the inset PMM (Figure 5b), which is $1.931 \mathrm{~T}$.

Figure 6 show the waveform of air-gap flux density of interior and inset PM motors, respectively. It seems that the interior PMM produces a more distorted sinusoidal waveform due to the high leakage flux (Figure 6a). However, the average flux density is higher at $0.471 \mathrm{~T}$, compared to the inset PMM, which is only $0.363 \mathrm{~T}$; due to the high magnetic permeability of the rotor body that makes it can carry more magnetic flux to cross the air gap.

The waveform of the air gap magnetic flux density of the inset PMM is smoother approaching the sinusoidal waveform (Figure 6b). The waveform distortion is caused by leakage flux that occurs in the parts of the permanent magnet, which are enclosed by the top teeth of the rotor slots. Leakage flux increases eddy current, thus decreases machine efficiency [23].

\section{B. Torque-speed characteristics}

The calculation results of the motor parameters on base speed are listed in Table 2. The motor characteristics, namely the torque-current phase angle and torque-speed curves, are obtained using (10) - (16). The value of $V_{\mathrm{t}}$ in (13) is varied by changing the current density. The simulation results are shown in Figure 7 for the inset PMM and Figure 8 for the interior PMMs.

Torque as a function of current phase angle in the field weakening region shown in Figure $7 a$ and Figure 8a corresponds with torque-speed curves shown in Figure $7 \mathrm{~b}$ and Figure $8 \mathrm{~b}$, respectively. The two motors' characteristics are similar in that the smaller the armature current, the smaller the current phase angle that cannot achieve the maximum speed. It is because the flux generated by the armature current is not adequate to weaken all the ones produced by the permanent magnet to increase the speed at a given voltage limit [2].

The curve with a dashed line is obtained using the base parameters in Table 2. It demonstrates that the inset PMM with a lower $\psi_{M}$ produces a higher rotation, approximately $4200 \mathrm{rpm}$, whereas the interior PMM produces $3162 \mathrm{rpm}$. Meanwhile, the 


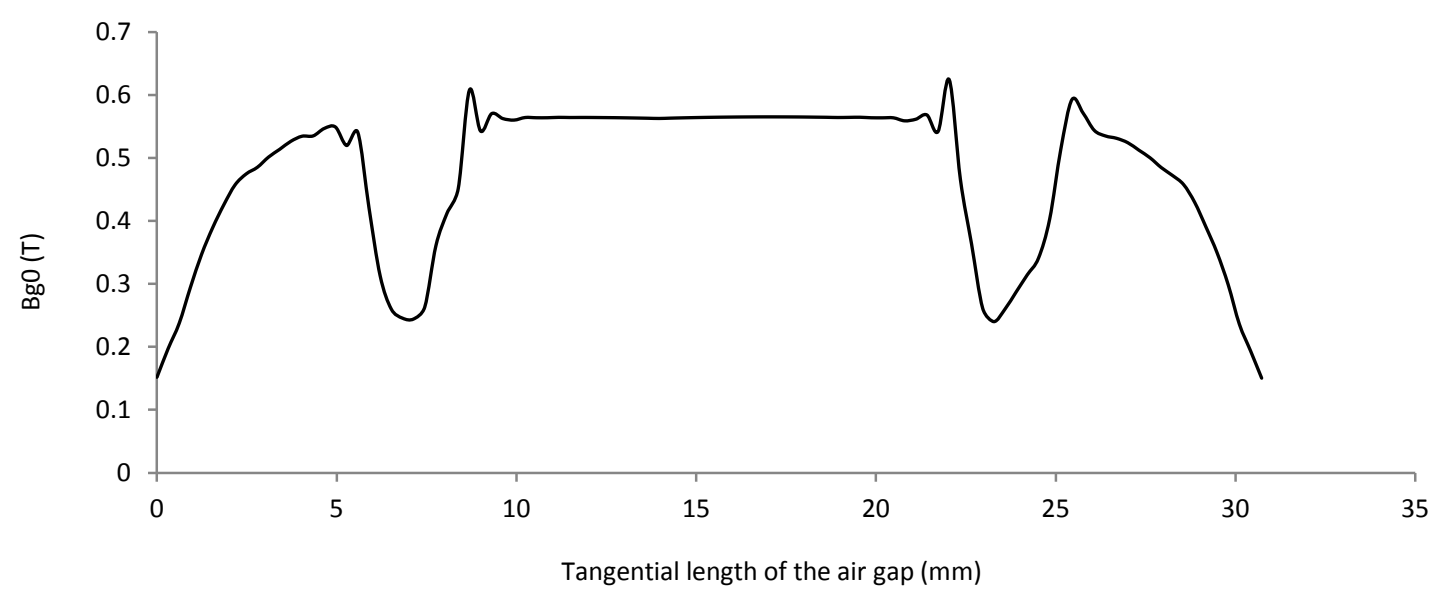

(a)

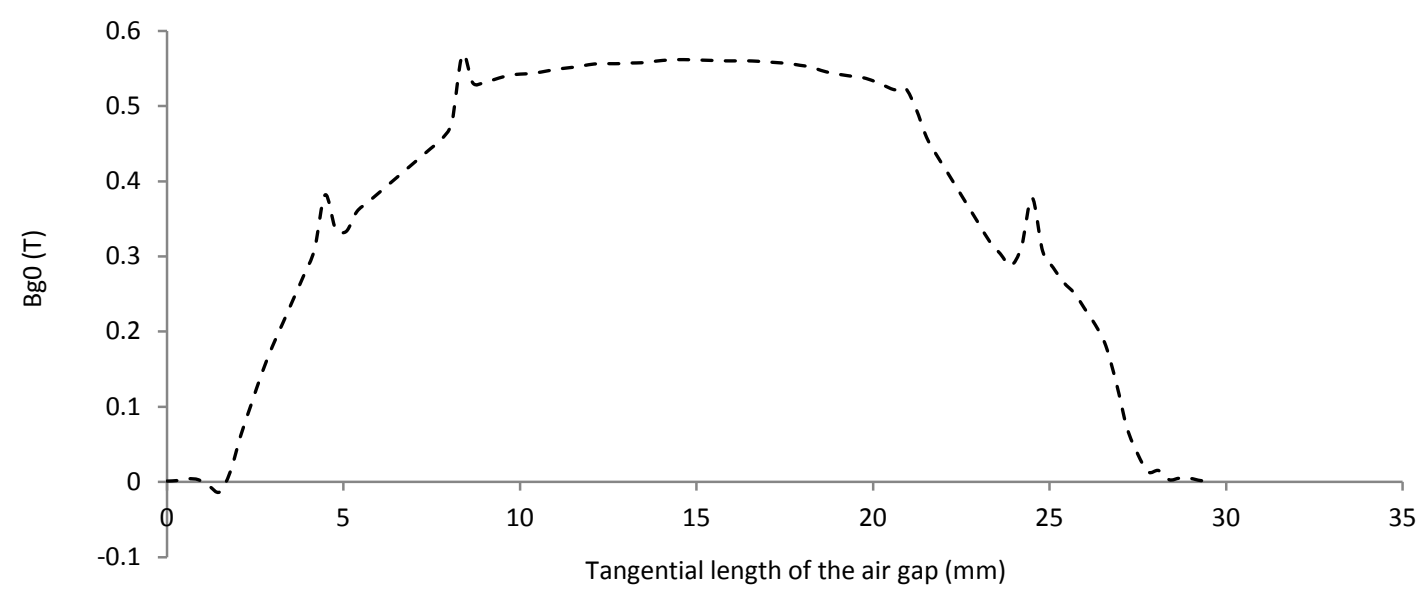

(b)

Figure 6. Air gap magnetic flux density waveform at no-load condition. (a) Interior PMM; (b) inset PMM

output torque of the interior PMM, on the other hand, is $56.47 \mathrm{Nm}$ greater than that of the inset PMM (46.01 Nm).

When the current increases beyond its base value, the torque and speed will also increase until they reach their maximum value. Maximum torque and speed, however, are not achieved at the same time. When the motor achieves maximum torque, its rotation slows slightly due to voltage saturation [2]. The inset PMM has a maximum rotation of $6259 \mathrm{rpm}$ but drops to $6212 \mathrm{rpm}$ when it reaches a maximum torque of $66.41 \mathrm{Nm}$. Meanwhile, the highest speed of the interior PMM is $6310 \mathrm{rpm}$, down to $6220 \mathrm{rpm}$ when it attains a maximum torque of $92.87 \mathrm{Nm}$. The maximum terminal voltage occurs when the motor reaches the maximum torque. It is $189.27 \mathrm{~V}$ for the interior PMM and $182.03 \mathrm{~V}$ for the PMM inset, respectively. The interior PMM can produce higher torque and a wider speed range due to the higher saliency ratio [24]. High output torque is needed by the vehicle to start moving from rest and to climbing, while a wide speed range provides comfort when cruising or driving, such as on the highway.

\section{Cogging torque}

The characteristic of cogging torque of both PMMs is exhibited in Figure 9. Cogging torque is greatly influenced by the magnitude of the magnetic flux in the air gap. Therefore, with higher $\psi_{M}$, interior PMM produces higher $T_{c}(2.90 \mathrm{Nm})$ than the inset one $(1.93 \mathrm{Nm})$.

Table 2.

Motor parameters on base speed

\begin{tabular}{llll}
\hline Parameter & Interior PM motor & Inset PM motor & \\
\hline Phase terminal voltage, $V$ & 149.93 & 158.03 & Unit \\
Phase induction voltage, $E_{\mathrm{ph}}$ & 133.85 & 128.86 & $\mathrm{~V}$ \\
Phase armature current, $I_{\mathrm{a}}$ & 14.73 & 12.46 & $\mathrm{~V}$ \\
Magnetic flux, $\psi_{M}$ & 0.6025 & 0.5801 & $\mathrm{~A}$ \\
Number of turns per phase $N_{\mathrm{ph}}$ & 96 & 120 & $\mathrm{~Wb}$ \\
Armature resistance, $R_{\mathrm{a}}$ & 0.27 & 0.4 & $\mathrm{turns}$ \\
d-axis inductance, $L_{\mathrm{d}}$ & 0.010 & 0.014 & $\mathrm{H}$ \\
q-axis inductance, $L_{\mathrm{q}}$ & 0.014 & 0.016 & $\mathrm{H}$ \\
Rotor saliency ratio, $L_{\mathrm{q}} / L_{\mathrm{d}}$ & 1.4 & 1.15 & \\
\hline
\end{tabular}



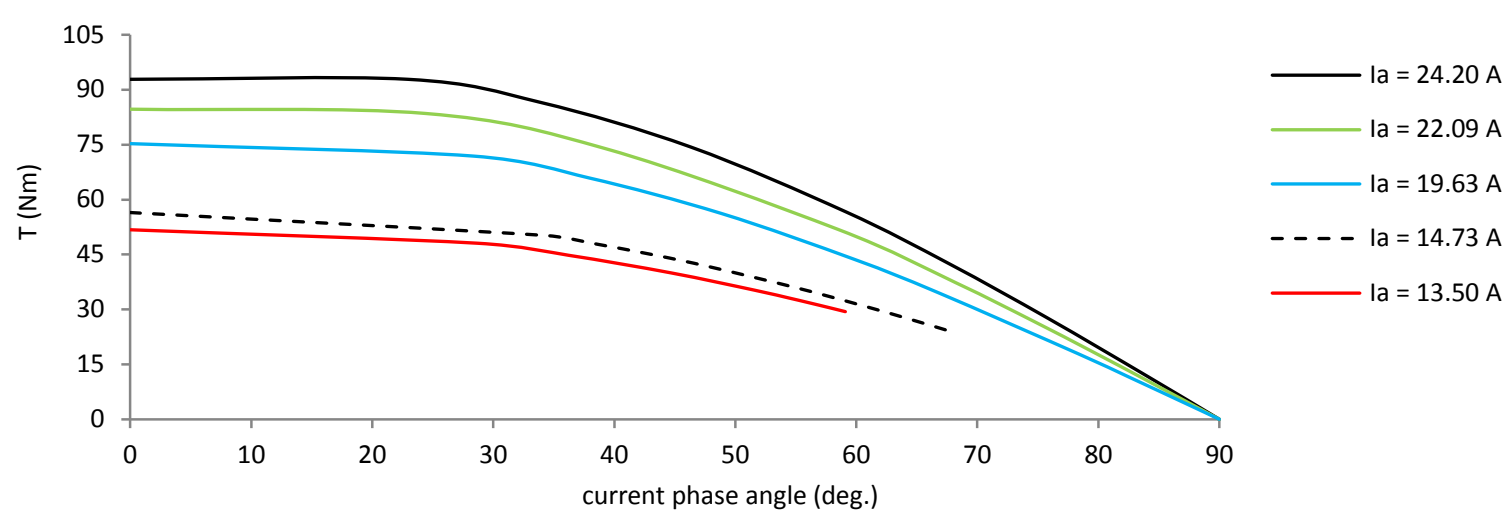

(a)

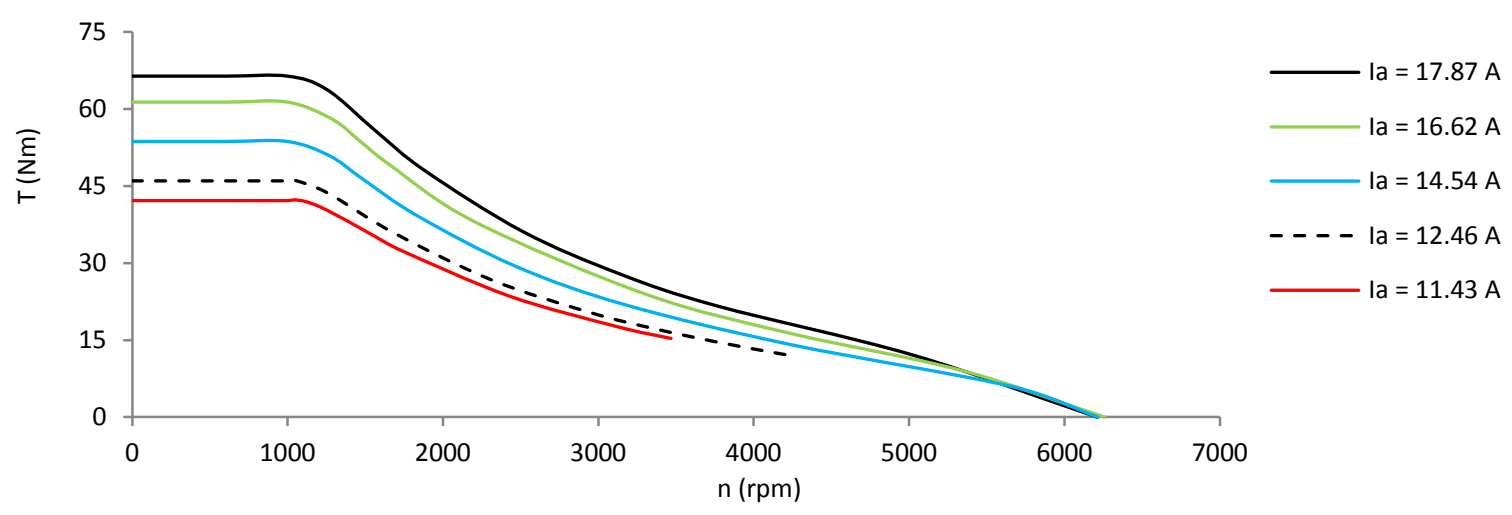

(b)

Figure 7. Inset PMM characteristics. (a) torque - current phase angle curve; (b) torque-speed curve

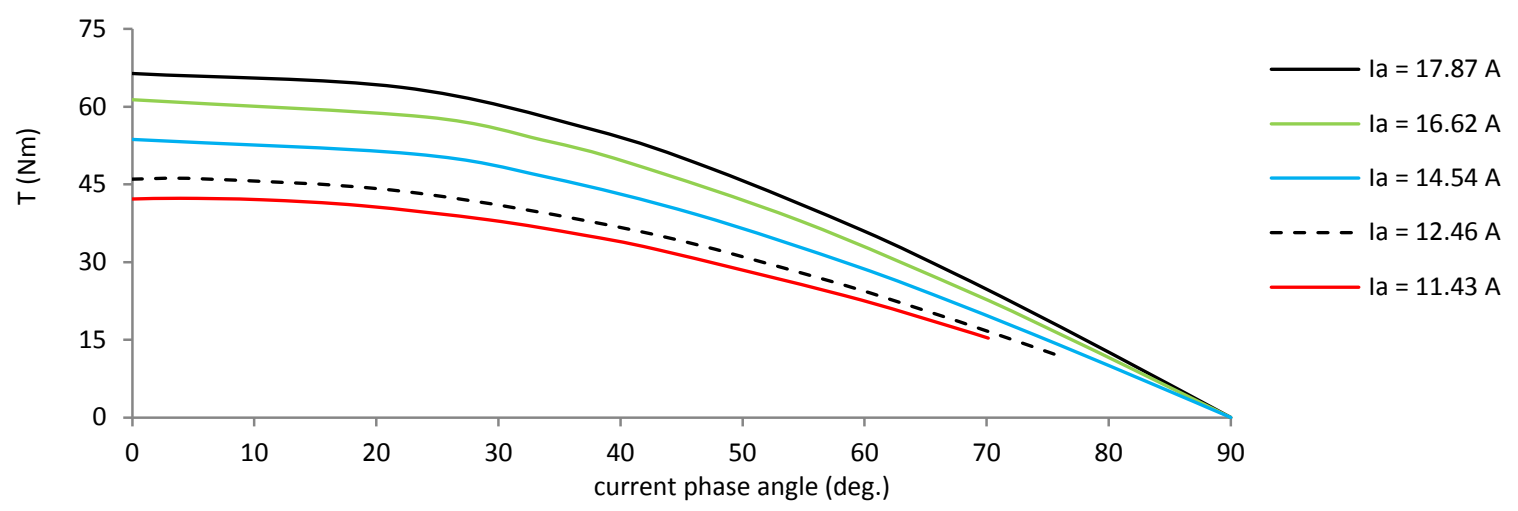

(a)

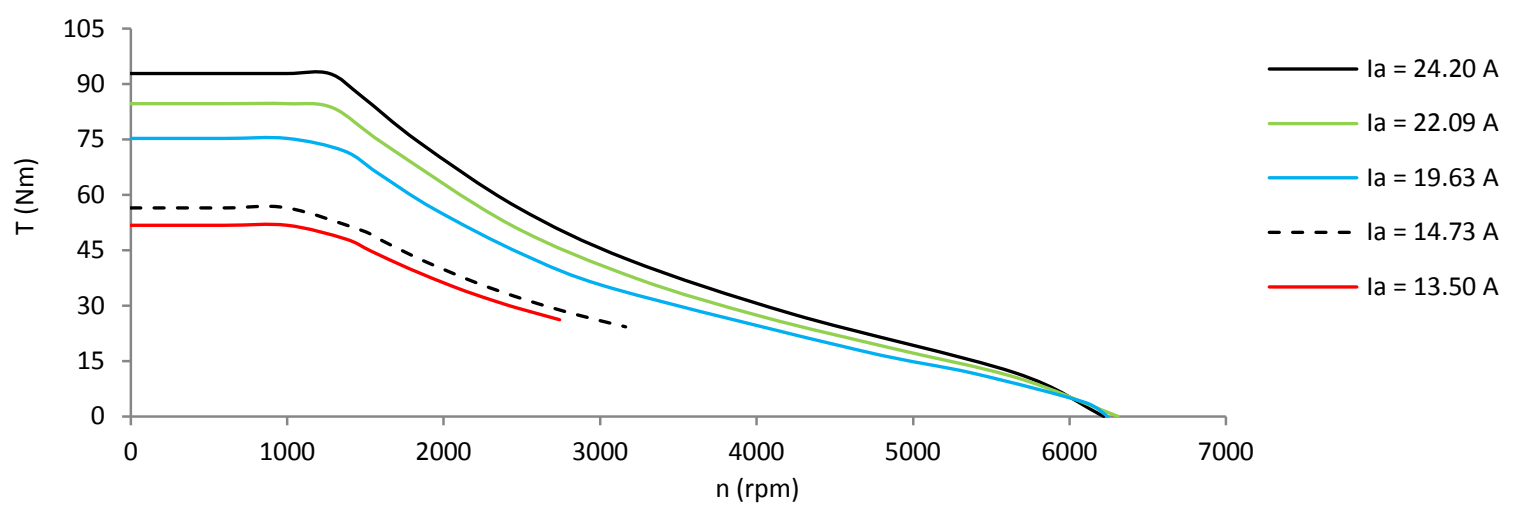

(b)

Figure 8. Interior PMM characteristics. (a) torque - current phase angle curve; (b) torque-speed curve 


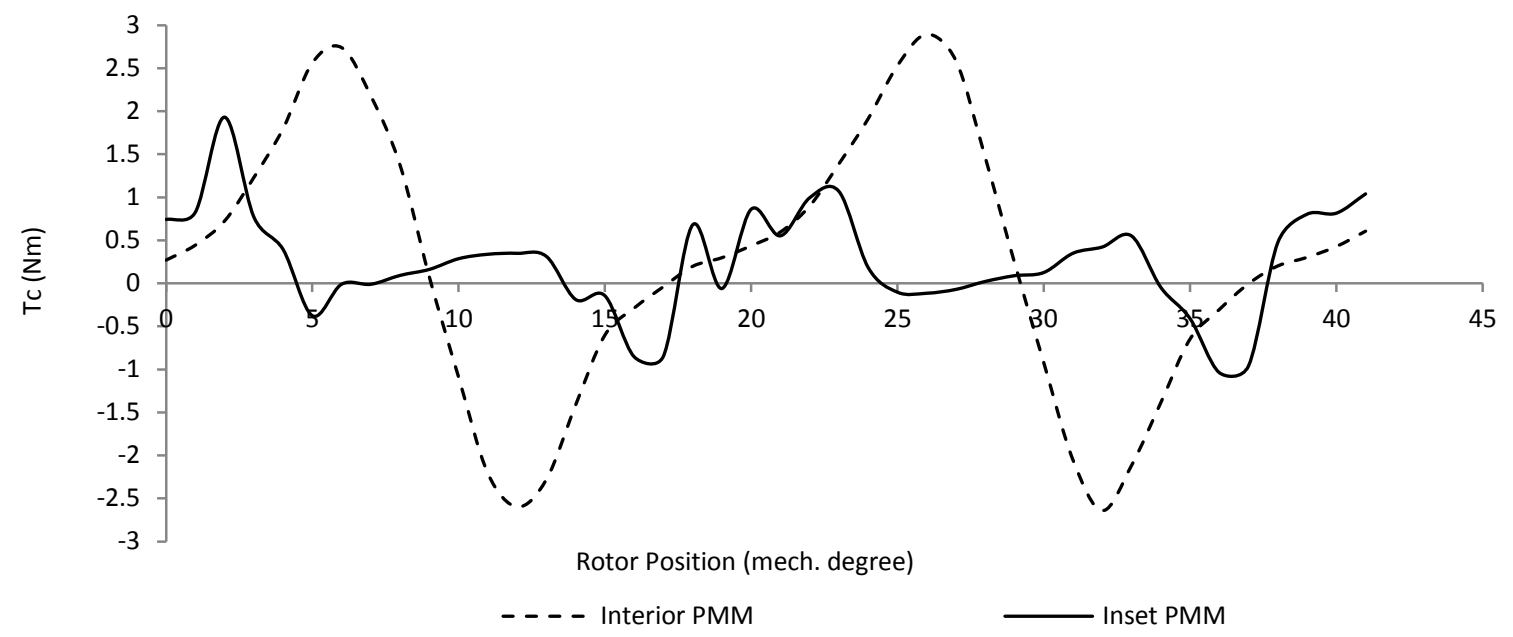

Figure 9. Cogging torque characteristics

The cogging torque waveform of the interior PMM is also smoother owing to the uniform air gap radial length. An uneven air gap increases the torque ripple [25], which can reduce bearing life, whereas a higher cogging torque requires a higher starting current to start rotating the motor. Cogging torque can be reduced by optimizing parameters, such as the pole arc to pole pitch ratio, stator slot opening width, etc.

\section{Conclusion}

This paper has discussed the comparison of interior and inset PMM characteristics for electric vehicle applications. The calculation and simulation results show that at the base speed, the interior $\mathrm{PMM}$ is superior in generating output torque (56.47 $\mathrm{Nm}$ ) but with a lower rotation (3162 rpm), while the PMM inset produces lower torque $(46.01 \mathrm{Nm})$ but higher rotation $(4200 \mathrm{rpm})$. A higher saliency ratio makes the interior PMM produces higher maximum torque and speed at both constant torque and field weakening regions than the PMM inset, which is $92.87 \mathrm{Nm}$ and $6310 \mathrm{rpm}$, respectively. Regarding the cogging torque, the interior PMM generates a little higher $(2.90 \mathrm{Nm})$ than the inset PMM $(1.93 \mathrm{Nm})$. From these results, it can be concluded that, in general, the interior PMM demonstrates better performance in all studied zones and is preferable for electric vehicle applications. However, design optimization needs to be done, specifically reducing the cogging torque.

\section{Acknowledgment}

The authors would like to thank Research Center for Electrical Power and Mechatronics, Indonesian Institute of Sciences for all the provided facilities.

\section{Declarations}

\section{Author contribution}

P. Irasari contributed as the main contributor of this paper. All authors read and approved the final paper.

\section{Funding statement}

This research did not receive any specific grant from funding agencies in the public, commercial, or not-forprofit sectors.

\section{Conflict of interest}

The authors declare no known conflict of financial interest or personal relationships that could have appeared to influence the work reported in this paper.

\section{Additional information}

Reprints and permission information is available at https://mev.lipi.go.id/.

Publisher's Note: Research Centre for Electrical Power and Mechatronics - Indonesian Institute of Sciences remains neutral with regard to jurisdictional claims and institutional affiliations.

\section{References}

[1] B. Qu, Q. Yang, Y. Li, M. A. Sotelo, S. Ma, and Z. Li, "A Novel Surface Inset Permanent Magnet Synchronous Motor for Electric Vehicles," Symmetry, vol. 12, pp. 1-14, 2020.

[2] T. A. Huynh and M.-F. Hsieh, "Performance Analysis of Permanent Magnet Motors for Electric Vehicles (EV) Traction Considering Driving Cycles " Energies, vol. 11, pp. 1-24, 2018.

[3] L. Petkovska and G. Cvetkovski, "Assessment of Torques for a Permanent Magnet Brushless DC Motor Using FEA," Przegląd Elektrotechniczny (Electrical Review), vol. 87, pp. 132-136, 2011.

[4] F. Erken, E. Öksüztepe, and H. Kürüm, "Online Adaptive Decision Fusion Based Torque Ripple Reduction in Permanent Magnet Synchronous Motor," IET Electric Power Applications, vol. 10, pp. 189- 196, 2016.

[5] Z. S. Du and T. A. Lipo, "Reducing Torque Ripple Using Axial Pole Shaping in Interior Permanent Magnet Machines," IEEE Transactions on Industry Applications, vol. 56, pp. 148-157, 2020.

[6] T. F. Janecek, J. M. Dyer, and K. Williams, "Cogging Torque Reduction Device for Electrical Machines," US Patent US9006951B2, 2015.

[7] G. J. Li, B. Ren, Z. Q. Zhu, Y. X. Li, and J. Ma, "Cogging Torque Mitigation of Modular Permanent Magnet Machines," IEEE Transaction on Magnetics, vol. X, pp. 1-10, 2015.

[8] J. R. B. A. Monteiro, A. A. O. Jr, M. L. Aguiar, and E. R. Sanagiotti, "Electromagnetic Torque Ripple and Copper Losses Reduction in Permanent Magnet Synchronous Machines," European Transactions on Electrical Power, vol. 22, pp. 627-644, 2011.

[9] G. G.-Lopez, M. Perisic, and S. Hiti, "Gain Adjustment to Improve Torque Linearity in a Field Weakening Region," US Patent US 8,228,016 B2, 2012. 
[10] M. T. Elsayed, O. A. Mahgoub, and S. A. Zaid, "Simulation Study of a New Approach for Field Weakening Control of PMSM," Journal of Power Electronics, vol. 12, pp. 136-144, 2012.

[11] F. Ma, H. Yin, L. Wei, G. Tian, and H. Gao, "Design and Optimization of IPM Motor Considering Flux Weakening Capability and Vibration for Electric Vehicle Applications," Sustainability, vol. 10, pp. 1-15, 2018.

[12] A. Rahideh, H. M.-Jahromi, M. Mardaneh, F. Dubas, and T. Korakianitis, "Analytical Calculations of Electromagnetic Quantities for Slotted Brushless Machines with Surface-Inset Magnets," Progress In Electromagnetics Research B, vol. 72, pp. 49- 65, 2017

[13] W. Zhao, T. A. Lipo, and B.-I. Kwon, "Optimal Design of a Novel Asymmetrical Rotor Structure to Obtain Torque and Efficiency Improvement in Surface Inset PM Motors," IEEE Transactions on Magnetics vol. 51, 2015.

[14] D. Matsuhashi, K. Matsuo, T. Okitsu, T. Ashikaga, and T. Mizuno, "Comparison Study of Various Motors for EVs and the Potentiality of a Ferrite Magnet Motor," IEEJ Journal of Industry Applications, vol. 4, pp. 174-179, 2015.

[15] A. Jabbari, "2D Analytical Modeling of Magnetic Vector Potential in Surface Mounted and Surface Inset Permanent Magnet Machines," Iranian Journal of Electrical \& Electronic Engineering, vol. 13, pp. 362-373, 2017.

[16] M. Ali, M. Hejra, and T. Hafedh, "On the Performances Investigation of Different Surface Mounted Permanent Magnet Machines," International Journal of Power Electronics and Drive System, vol. 6, pp. 509-515, 2015.

[17] H. Chengyuan, "Design of High Efficiency Brushless Permanent Magnet Machines and Driver System," Doctoral Thesis, Electrical and Computer Engineering, University of Central Florida, Orlando, Florida, 2018.

[18] K. Wirtayasa, P. Irasari, M. Kasim, P. Widiyanto, and M. F. Hikmawan, "Load Characteristic Analysis of a Double-side
Internal Coreless Stator Axial Flux PMG," Journal of Mechatronics, Electrical Power, and Vehicular Technology, vol. 10 , pp. $17-23,2019$

[19] M. R. Khowja, G. Vakil, and C. Gerada, "Analytical Tool to Generate Torque-Speed Characteristics for Surface Mounted PM Machines in Constant Torque and Field Weakening Regions," in IECON 2019 - 45th Annual Conference of the IEEE Industrial Electronics Society, Lisbon, Portugal, 2019, pp. $922-$ 927. 6

[20] B. M. Wilamowski and J. D. Irwin, Power Electronics and Motor Drives, Second ed. Boca Raton, FL: CRC Press, 2011.

[21] X. Zhang, J. Ji, J. Zheng, and X. Zhu, "Improvement of Reluctance Torque in Fault-Tolerant Permanent-Magnet Machines With Fractional-Slot Concentrated-Windings," IEEE Transactions on Applied Superconductivity, vol. 28, 2018.

[22] M. G.-Gracia, Á. J. Romero, J. H. Ciudad, and S. M. Arroyo, "Cogging Torque Reduction Based on a New Pre-Slot Technique for a SmallWind Generator," Energies, vol. 11, pp. 115, 2018.

[23] M. Satoa, M. Nireib, Y. Yamanakaa, T. Suzukia, Y. Bua, and T. Mizunoa, "Increasing the Efficiency of a Drone Motor by Arranging Magnetic Sheets to Windings," Energy Reports vol. 6, pp. 439- 446, 2020 .

[24] Z. Zhang, C. Xia, H. Wang, and T. Shi, "Analytical Field Calculation and Analysis of Surface Inset Permanent Magnet Machines With High Saliency Ratio," IEEE Transactions on Magnetics, vol. 52, 2016.

[25] J. Liang, A. Parsapour, Z. Yang, C. C.-Narvaez, M. Moallem, and B. Fahimi, "Optimization of Air-Gap Profile in Interior Permanent-Magnet Synchronous Motors for Torque Ripple Mitigation," IEEE Transactions on Transportation Electrification, vol. 5, pp. 118-125, 2019. 